\title{
Instrumental aversive conditioning in the Skink Eumeces Inexpectatus studied with two test chambers $^{1}$
}

\author{
ROBERT W. POWELL and KATHLEEN \\ PECK, University of South Florida, \\ Tampa, Fla. 33620
}

Instrumental aversive conditioning was studied in Florida five-lined skinks in two similar test situations. All animals showed general decreases in escape latencies. Only a small number of avoidances occurred, but these tended to increase over trials. The avoidance responses do not seem attributable to spontaneous running.

Escape conditioning has been demonstrated with several reptilian species, including alligators (Davidson, 1966), snakes (Kellog \& Pomeroy, 1936; Crawford \& Holmes, 1966), caimans (Williams, 1967), and lizards (Powell, 1967, 1968; Powell \& Mantor, 1969). None of these investigators found avoidance learning in the species they studied. Rather marked performance decrements occurred in some of the animals studied by Williams (1967), Powell (1968), and Powell \& Mantor (1969). The deterioration in performance seemed to result from the cumulative effects of electric shock that was employed as the aversive stimulus. In addition, the lizard species employed in earlier studies in this laboratory (Anolis carolinensis, Anolis sagrei) have often failed to adapt to the laboratory regimen. For this reason, it has been necessary to discard a number of animals in the course of an experiment, because they became generally debilitated.

The primary purpose of the present experiment was to study instrumental aversive conditioning in a different lizard species, the Florida five-lined skink (Eumeces inexpectatus). This species is a thick-bodied, medium-sized lizard that appears quite robust. Prior to the experiment, we found that skinks remained in good condition during several months in captivity. They were observed to feed more readily than had the Anoles studied earlier.

A second purpose of the experiment was to study two similar test chambers in terms of their relative effectiveness in promoting escape and/or avoidance responding in lizards.

\section{SUBJECTS}

Four Florida five-lined skinks were used that ranged in size from 3 to $3 \frac{1}{2}$ in. (snout to vent). The animals were caught locally in the field and were housed in partitioned sections of a 20 -gal aquarium. Water and live crickets and mealworms were provided as food. Temperature in the living and experimental areas remained at approximately $72^{\circ} \mathrm{F}$.

\section{APPARATUS}

Two test chambers, which differed in basic configuration, were employed. Both chambers permitted one-way shuttle conditioning and did not require direct handling of the lizards between trials. During conditioning, each chamber was placed upon a grid of stainless steel rods, except for the goal compartment, which rested on a wooden platform. Shock, which was scrambled to the grid, was provided by a Lehigh Valley shock source, Model 1599A. Shock intensities ranged from .40 to $.90 \mathrm{~mA}$. A Lehigh Valley photosensor, Model 1553, was positioned at the entrance to the goal compartment. When activated by the animal, it stopped a running time meter and turned off the experimental stimuli.

Test Chamber 1 consisted of the bilateral halves of the globe portion of a $500-\mathrm{ml}$ Florence boiling flask. The globe halves were interchanged as starting and goal compartments. A 4-in.-long bilateral section of the flask neck, which served as the runway, was flush-mounted to wooden supports.

Test Chamber 2 was constructed of $1 / 4-i n$. clear Plexiglas. It consisted of three triangular compartments, each of which was formed by mounting two pieces of Plexiglas, 5 in. long $\times 3 \frac{1}{4}$ in. high, at a 90-deg angle along their length. At their base, where they rested on the grid, the sides of the compartment were $4 \frac{1}{4} \mathrm{in}$. apart. The three compartments were aligned to form startbox, runway, and goalbox. The start- and goalboxes, which were interchanged, had detachable steel end plates that were held in place by small magnets. The lower 2/4 in. of each Plexiglas partition was painted dark blue, so it was opaque.

A $15-$ W bulb was mounted in a movable support so that it could be placed above the goalbox. A 7-in. Argos speaker, connected to a Precision sine square-wave generator, Model E-310, was placed approximately $8 \mathrm{in}$. from the test chamber. This provided a square-wave signal of $5,000 \mathrm{~Hz}$ at approximately $85 \mathrm{~dB}$.

\section{PROCEDURE}

Prior to each experimental session, a small amount of Vaseline jelly was smeared on each of the skinks' feet in order to decrease skin resistance. Measurements of resistance in the skinks, from the fore to the hind legs, ranged from $100 \mathrm{~K}$ to $500 \mathrm{~K}$ dry and from $60 \mathrm{~K}$ to $200 \mathrm{~K}$ with Vaseline.

At the start of each session, the skink was placed in the start compartment with the gate blocking the runway. Each trial started with three simultaneous events: (1) illumination of the $15-\mathrm{W}$ bulb above the goal compartment, (2) onset of the auditory signal, and (3) withdrawal of the gate. The tone and light continued for $70 \mathrm{sec}$, with shock starting $10 \mathrm{sec}$ after their onset. If the animal responded by running to the goal compartment, thereby activating the photosensor, the compound CS and shock, if present, were terminated. Responses prior to shock onset were considered avoidance, while those following it were considered escape. If the skink did not make either type of response, the experimental stimuli were terminated after $70 \mathrm{sec}$ ( $60 \mathrm{sec}$ of shock).

When the animal ran to the goalbox during a trial, the two end compartments were switched after $30 \mathrm{sec}$ and the wooden floor was removed and placed under the compartment now serving as the goalbox. Experimental sessions consisted of 15 trials per day, with $60 \mathrm{sec}$ between trials.

All animals were studied first in Test Chamber 1. Training continued until the skink showed no improvement in mean response time over 100 consecutive trials, or until approximately 400 trials were completed. After a lapse of approximately 2 weeks, in which no training was given, three of the skinks $(2$, $3,5)$ were studied in Test Chamber 2. The same criteria were employed, except that training was terminated after approximately 350 trials.

Control trials only were conducted during the first two sessions in each test chamber. These trials were identical to the conditioning trials, except that no shock was presented. The shock intensities used during conditioning trials ranged from .40 to $.90 \mathrm{~mA}$.

\section{RESULTS AND DISCUSSION}

Only a small number of avoidance responses occurred in either test chamber,

Table 1

The Number of Avoidance Responses Which Occurred During Each Succeeding Quarter of the Trials for Each Skink in Each Test Chamber

\begin{tabular}{lrrrrr} 
& $\begin{array}{l}\text { 1st } \\
\text { Qtr }\end{array}$ & $\begin{array}{r}\text { 2nd } \\
\text { Qtr }\end{array}$ & $\begin{array}{r}\text { 3rd } \\
\text { Qtr }\end{array}$ & $\begin{array}{r}\text { 4th } \\
\text { Qtr }\end{array}$ & Total \\
\hline Test Chamber 1 & & & & & \\
$\quad$ Skink 1 & 0 & 1 & 4 & 10 & 15 \\
Skink 2 & 0 & 2 & 1 & 0 & 3 \\
Skink 3 & 0 & 0 & 0 & 1 & 1 \\
Skink 5 & 0 & 0 & 0 & 0 & 0 \\
Test Chamber 2 & & & & & \\
Skink 2 & 0 & 0 & 0 & 0 & 0 \\
Skink 3 & 1 & 5 & 4 & 4 & 14 \\
Skink 5 & 0 & 0 & 1 & 7 & 8 \\
\hline
\end{tabular}




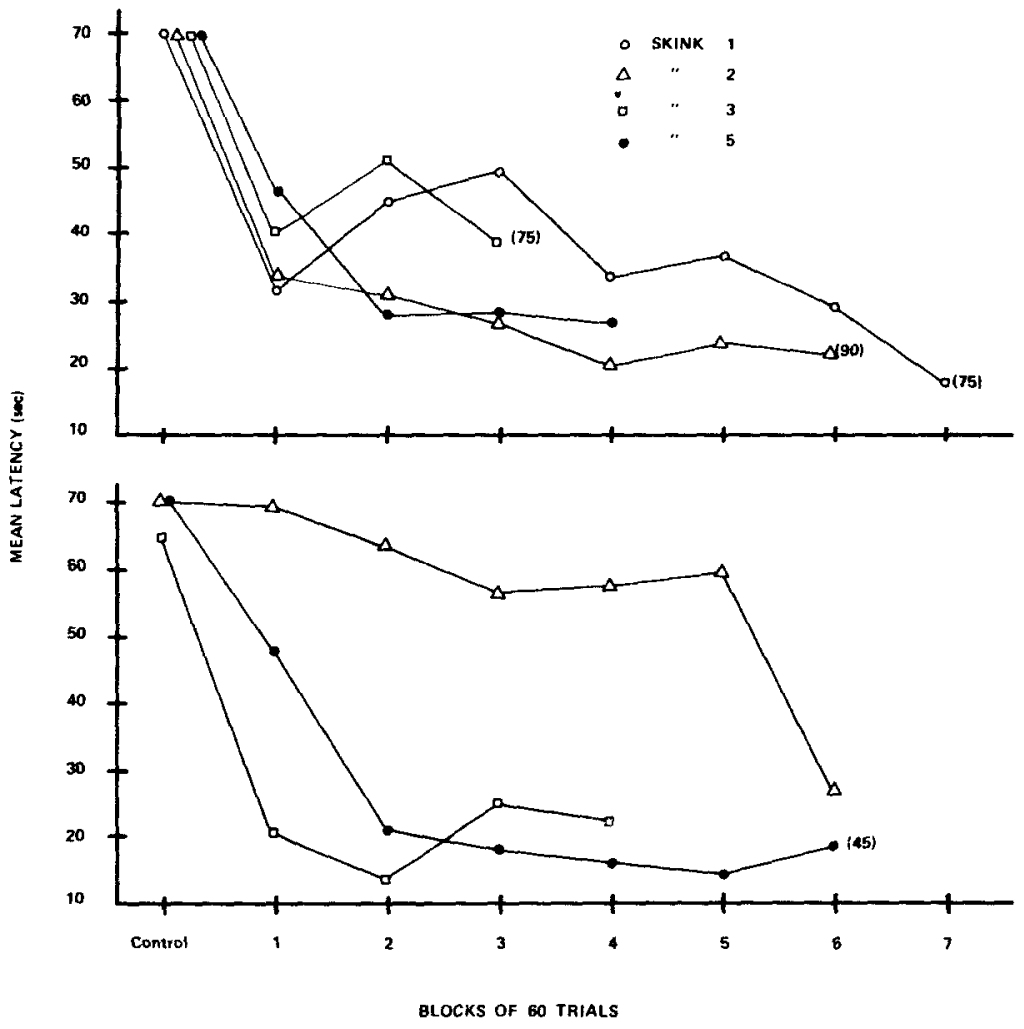

as Table 1 shows. However, the number of avoidance responses did tend to increase over trials. In addition, a comparison of the present results with two earlier studied (Powell, 1968; Powell \& Mantor, 1969) reveals that only $0.85 \%$ of the responses made by Cuban Anoles (Anolis sagrei) were avoidance. The percentage of avoidances made by the skinks was $1.51 \%$ in Test Chamber 1 and $2.33 \%$ in Test Chamber 2. While these differences are small, it does appear that the avoidance responses made by the skinks cannot be readily attributed to spontaneous running.

Figure 1 shows that escape latencies generally decreased over trials. Two of the skinks $(3,5)$ performed better in Test Chamber 2, while the third skink (2) had shorter latencies in Test Chamber 1. Spontaneous running during control trials was negligible, occurring on only $1.54 \%$ of the trials. None of these responses occurred during the first $10 \mathrm{sec}$ of a trial, which would correspond to an avoidance. This reinforces the idea that the avoidance responses that occurred during conditioning were not spontaneous running responses.

The escape latencies obtained here were generally not as short as those displayed by Cuban Anoles (Powell, 1968). This suggests that the shock intensities employed in the present experiment may not have been sufficiently intense. None of the skinks displayed cumulative shock effects and all survived the experiment in good condition, except for Skink 1. This animal died in an accident that was unrelated to the experiment.

The results, overall, indicate that Test
Fig. 1. The mean response latency averaged over successive blocks of 60 trials each. The numbers in parentheses indicate the number of trials that the corresponding data point is based upon when it differed from 60 . Each data point that corresponds to the "control" notation on the abscissa is based upon 30 trials.

Chamber 2 produced slightly better performance than Test Chamber 1 and should be favored in future experiments. The Florida five-lined skink proved to be a very durable $S$, so its behavior was studied over many more trials than had been possible with Cuban Anoles. It is suggested that the use of higher shock intensities, with perhaps shorter trials, should produce shorter escape latencies and possibly a larger number of avoidance responses.

\section{REFERENCES}

CRAWFORD, F. T., \& HOLMES, C. E. Escape conditioning in snakes employing vibratory stimulation. Psychonomic Science, 1966, 4 , 125-126.

DAVIDSON, R. W. Operant stimulus control applied to maze behavior: Heat escape conditioning and discrimination reversal in alligator Mississippiensis. Journal of the Experimental Analysis of Behavior, 1966, 9, 671-676.

KELLOGG, W. N., \& POMEROY, W. B. Maze learning in water snakes. Journal of Comparative Psychology, 1936, 21, 275-295.

POWELL, $R$. W. Avoidance and escape conditioning in lizards. Psychological Reports, 1967, 20, 583-586.

POWELL, R. W. A readily-available test chamber used in the study of shuttle escape and avoidance in the lizard Anolis sagrei. Psychological Record, 1968, 18, 585-590.

POWELL, R. W., \& MANTOR, H. Failure to obtain one-way shuttle avoidance in the lizard Anolis sagrei. Psychological Record, in press. WILLIAMS, J. T. Efficient motivation for studying crocodilian learning. Psychonomic Science, 1967, 8, 279. NOTE

1. The authors wish to express their gratitude to Stephen Peck, for his assistance in the experiment, and also to Faulkner Plastics, Inc., for the contribution of Plexiglas used in the experiment. Reprints may be obtained from Robert W. Powell, Department of Behavioral Science, University of South Florida, Tampa, Fla. 33620 . 